\title{
Simulasi Vending Machine Dengan Mengimplementasikan Finite State Automata
}

\author{
Tri Ichsan Saputra, Fauziah, Aris Gunaryati \\ triichsan1@gmail.com, fauziah@civitas.unas.ac.id, umidanti@gmail.com
}

Universitas Nasional

\begin{abstract}
In theory of language and automata explain about abstract machine which in there is finite state automata which can be implemented into vending machine. Vending machine for a city like Jakarta is not a difficult subject to find it. Operational way is already widely known procedures, but about how it works in the machine, still not many know it, through this simulation is expected the user also better understand it.
\end{abstract}

\begin{abstract}
Abstrak-Pada teori bahasa dan automata menjelaskan tentang mesin-mesin abstrak yang mana didalamnya terdapat finite state automata yang bisa diimplementasikan kedalam vending machine. Vending machine untuk kota seperti Jakarta sudah bukan perihal sulit untuk menemukannya. Cara kerja secara operasional sudah banyak diketahui prosedurnya, namun perihal bagaimana cara kerjanya didalam mesin tersebut, masih belum banyak yang mengetahuinya, melalui simulasi ini diharapkan pengguna juga lebih paham akan hal itu.
\end{abstract}

Kata Kunci : Vending Machine, Simulasi, Finite State, Bahasa dan Automata.

\section{PENDAHULUAN}

Teori automata sangat erat kaitannya dengan mesin-mesin abstrak. Sedangkan teori bahasa erat kaitannya dengan komunikasi atau penghubung baik antara sesama manusia maupun dengan yang lainnya, jika diambil dalam materi ini maka bahasa adalah media antara manusia dengan komputer untuk saling berinteraksi[1].

Dari jenisnya yaitu finite state automata terdapat mesin bahasa yang berarti dia dapat mengenali, menerima dan menolak yang terdapat pada mesin FSA jenis DFA (Deterministic Finite Automata) dan NFA (Non-deterministic Finite Automata)[2]. Dan ada FSA output yang mana berbeda dengan jenis FSA sebelumnya (DFA \& NFA), pada jenis ini tidak terdapat state menerima dan menolak, memiliki fungsi \& himpunan output[3].

Sebagai contoh mesin FSA output bisa dengan menggunakan simulasi vending machine yang mana konsep dasar dari alat tersebut adalah metode FSA output. Sebuah vending machine biasanya menjual 1 (satu) jenis barang, seperti : makanan ringan (snack), minuman, pembelian tiket seperti halnya di KRL, dan sebagainya[4]. Walaupun di Indonesia, khususnya Jakarta sudah banyak penggunaan vending machine, namun terlintas dalam benak untuk mengetahui dan mempelajari proses dari vending machine tersebut[5].

\section{METODE PENELITIAN}

Metode yang digunakan yaitu dengan menggunakan finite state, yang mana jika diambil contoh kasus sebagai berikut:

Tuple M pada FSA jenis DFA maupun NFA diantaranya $(\mathrm{Q}, \Sigma, \delta, \mathrm{S}, \mathrm{F})$ yang mengartikan untuk $\mathrm{Q}=$ himpunan state, $\Sigma=$ himpunan input, $\delta$ =fungsi transisi, $\mathrm{S}=$ state awal, $\mathrm{F}=$ state akhir. Disini sebagai contoh sederhana, kita gunakan FSA jenis DFA[6].

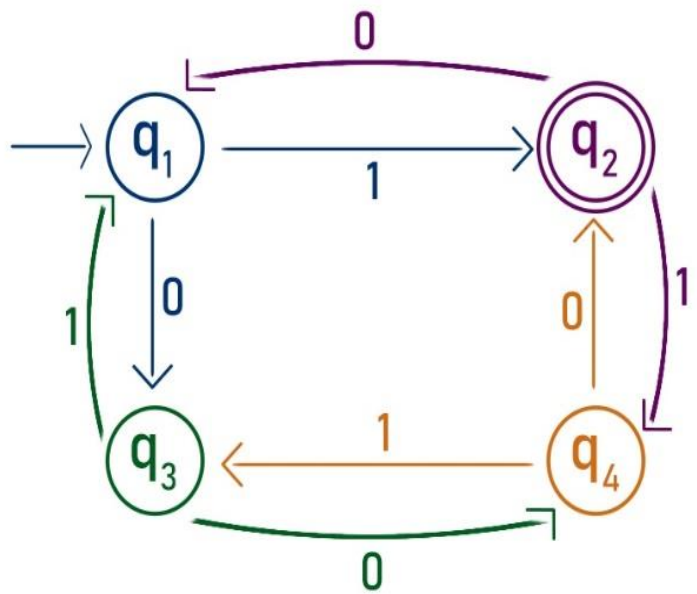

Gambar 1: Diagram DFA

Dari diagram diatas, kita bisa melihat bahwa tuplenya sebagai berikut :

$\mathrm{Q}=(\mathrm{q} 1, \mathrm{q} 2, \mathrm{q} 3, \mathrm{q} 4), \Sigma=(0,1), \mathrm{S}=(\mathrm{q} 1), \mathrm{F}=(\mathrm{q} 2)$

Fungsi transis $i=\delta$

$\delta(\mathrm{q} 1,0)=\mathrm{q} 3, \quad \delta(\mathrm{q} 1,1)=\mathrm{q} 2, \quad \delta(\mathrm{q} 2,0)=\mathrm{q} 1, \quad \delta(\mathrm{q} 2,1)=\mathrm{q} 4, \quad \delta(\mathrm{q} 3,0)=\mathrm{q} 4$, $\delta(\mathrm{q} 3,1)=\mathrm{q} 1, \quad \delta(\mathrm{q} 4,0)=\mathrm{q} 2, \quad \delta(\mathrm{q} 4,1)=\mathrm{q} 3$ 
Dari fungsi transisi tersebut maka dapat dilihat tabel transisi sebagai berikut :

Table 1: Tabel Transisi

\begin{tabular}{|c|c|c|}
\hline$\delta$ & 0 & 1 \\
\hline $\mathrm{q} 1$ & $\mathrm{q} 3$ & $\mathrm{q} 2$ \\
\hline $\mathrm{q} 2$ & $\mathrm{q} 1$ & $\mathrm{q} 4$ \\
\hline $\mathrm{q} 3$ & $\mathrm{q} 4$ & $\mathrm{q} 1$ \\
\hline $\mathrm{q} 4$ & $\mathrm{q} 2$ & $\mathrm{q} 3$ \\
\hline
\end{tabular}

Sebagai contoh, misal kita input '1111', maka untai akan bergerak dari state awal (q1) kemudian input ' 1 ' pertama berubah posisi menjadi (q2) lalu input kembali ' 1 ' maka posisi pindah menjadi (q4), kemudian input kembali ' 1 ', maka posisi akan pindah kembali menjadi (q3), dan input kembali ' 1 ' yang terakhir, maka posisi akan berakhir pada (q0) dan hasilnya akan ditolak karena tidak berakhir di state penerima / finish stat[7]e.

Kasus diatas sudah menggambarkan sebagian kecil dari proses yang ada didalam vending machine, sama halnya seperti kasus diatas, nantinya jika nilai input (uang) kurang dari harga yang ada pada vending machine, maka output (minuman) tidak akan keluar[8].

\section{A. Perancangan Sistem}

Sistem dirancang dengan menggunakan UML (Unified Modelling Language) yang terdiri dari use case diagram dan activity diagram [9].

Usecase diagram mendeskripsikan sistem dari sudut pandang user, usecase diagram digunakan untuk melihat secara visual bagaimana simulasi perwujudan atau interaksi kejadian yang terjadi antara pengguna dengan vending machine dan apa yang dapat dilakukan oleh user, user dibagi menjadi dua user, yaitu user itu sendiri dan admin.

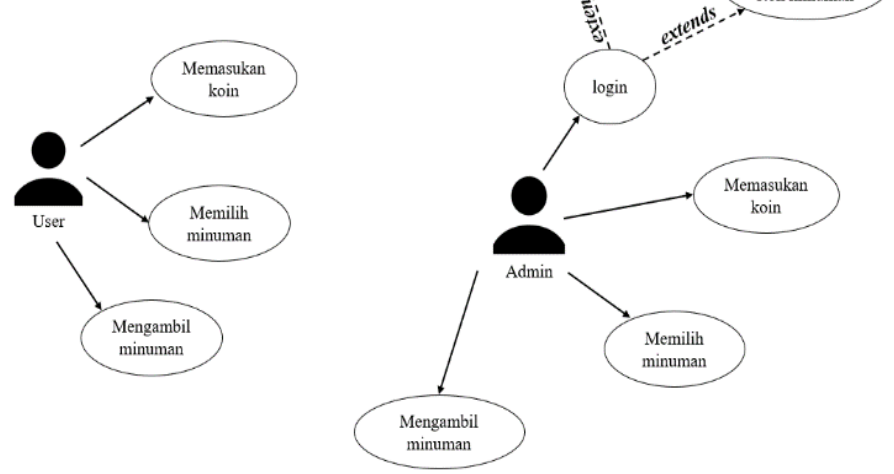

Gambar 2: (a) Usecase diagram user (b) Usecase diagram admin
Usecase diagram user dapat dilihat pada gambar 2(a), setelah menjalankan aplikasi, user dapat melakukan hal sebagai berikut; memasukan koin, memilih minuman dan mengambil minuman.

Kemudian dalam usecase diagram admin yang ada pada gambar 2(b), admin dapat melakukan hal yang dapat dilakukan oleh user dan juga dapat login untuk melakukan hal perihal mengambil koin atau menambah stok minuman.

Activity diagram menggambarkan sebuah alur dari rangkaian kegiatan yang ada pada sistem yang sedang dirancang. Jika vending machine dijalankan oleh user, maka activity diagram akan tergambar seperti gambar 3 .

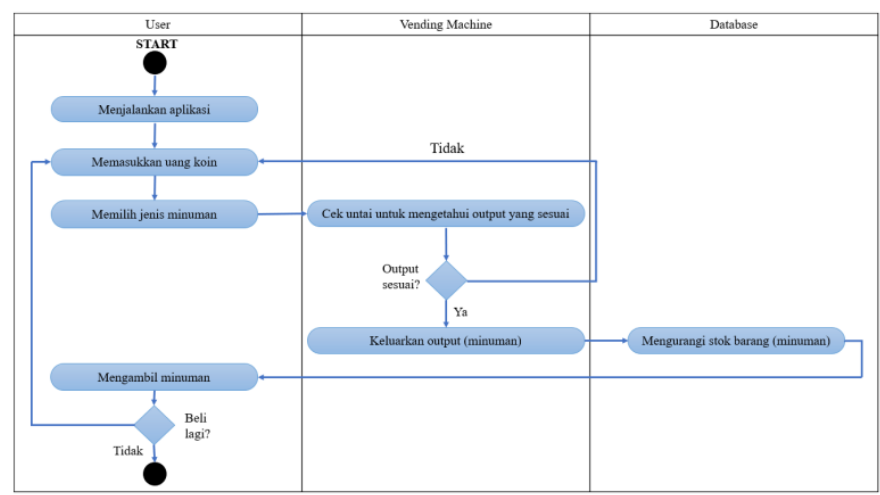

Gambar 3: Activity Diagram User

User mulai menjalankan aplikasi, kemudian memasukkan uang dan memilih jenis minuman yang diinginkan, kemudian sistem akan mengecek dan menyamakan antara input (uang) dan output (minuman) yang dipilih, jika sudah sesuai, maka vending machine akan mengeluarkan output (minuman) sesuai keinginan dan database akan mengurangi stok minuman, lalu tahap terakhir, user mengambil minuman yang telah dikeluarkan vending machine[10]. Dan jika user ingin membeli lagi, alurnya akan terulang mulai dari memasukkan koin ke vending machine.

Kemudian activity diagram admin dapat dilihat pada gambar $4[11]$.

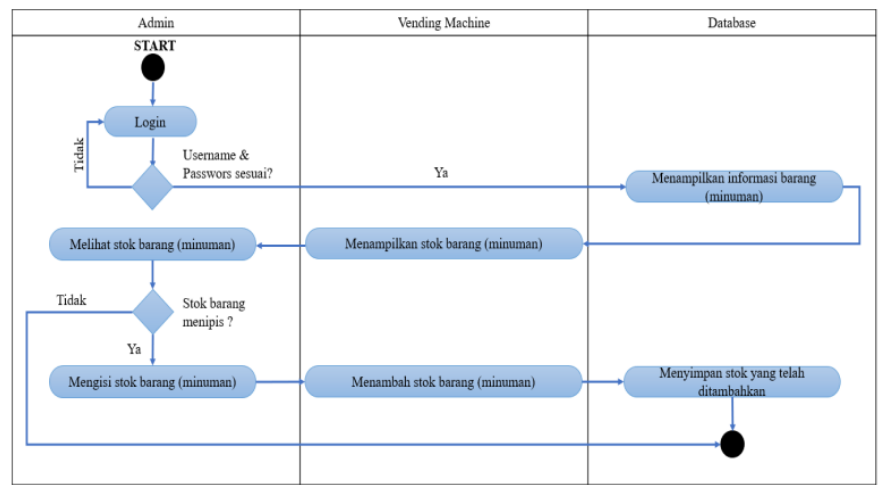

Gambar 4: Activity Diagram Admin

Activity diagram admin berbeda, disini activity diagram tergambar perihal mengisi ulang stok minuman. 
Dimulai dari login, jika username dan password tidak sesuai maka harus mengulang hingga username dan password sesuai, kemudian database akan menampilkan informasi minuman yang akan tampil didalam vending machine, kemudian admin melihat stok minuman, jika dirasa telah menipis maka ditambahkan, dan jika tidak, activity diagram selesai sampai disitu.

\section{B. Perancangan Diagram State}

Untuk merancang simulasi ini dibutuhkan diagram state yang digunakan untuk mengetahui cara kerja dari simulasi vending machine ini, semua nominal dengan minuman tidak sesuai hanya dibuat perumpamaan untuk mendeskripsikannya.

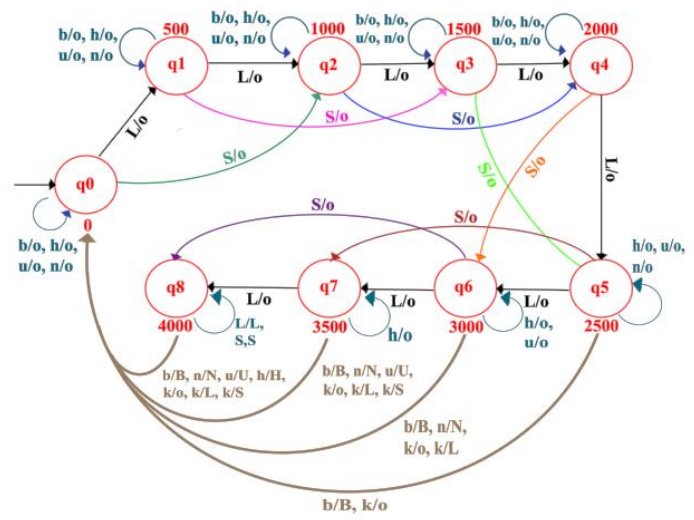

Gambar 5: Diagram State FSA Output

Gambar 5 menjelaskan bahwa terdapat beberapa input, sebagai berikut : k (kembalian), L (logam 500), S (logam 1000), b (pilih Buavita), n (pilih Nescafe), u (pilih Ultra Milk), $\mathrm{H}$ (pilih Hilo). Dan dengan output, diantaranya : o (tidak ada), B (keluar Buavita), N (keluar Nescafe), U (keluar Ultra Milk), H (keluar Hilo).

\section{Pendefinisian Tuple}

FSA Output didefinisikan sebagai berikut:

$\mathrm{M}=(\mathrm{Q}, \Sigma, \delta, \mathrm{S}, \Delta, \lambda)$

Yang mana:

$\mathrm{Q}=$ himpunan state, $\Sigma=$ himpunan simbol input, $\delta=$ fungsi transisi, $\mathrm{S}=$ state awal, $\Delta$ =himpunan simbol output, $\lambda=$ fungsi output.

Sehingga dapat didefinisikan sebagai berikut:

$\mathrm{Q}=\{\mathrm{q} 0, \mathrm{q} 1, \mathrm{q} 2, \mathrm{q} 3, \mathrm{q} 4, \mathrm{q} 5, \mathrm{q} 6, \mathrm{q} 7, \mathrm{q} 8\}$

$\Sigma=\{\mathrm{b}, \mathrm{n}, \mathrm{u}, \mathrm{h}, \mathrm{L}, \mathrm{S}, \mathrm{k}\}$

$\delta(\mathrm{q} 0, \mathrm{~b})=\mathrm{q} 0 ; \quad \delta(\mathrm{q} 0, \mathrm{n})=\mathrm{q} 0 ; \quad \delta(\mathrm{q} 0, \mathrm{u})=\mathrm{q} 0 ; \quad \delta(\mathrm{q} 0, \mathrm{~h})=\mathrm{q} 0 ;$ $\delta(\mathrm{q} 0, \mathrm{~L})=\mathrm{q} 1 ; \quad \delta(\mathrm{q} 0, \mathrm{~S})=\mathrm{q} 2 ; \quad \delta(\mathrm{q} 0, \mathrm{k})=\mathrm{q} 0 ;$

$\delta(\mathrm{q} 1, \mathrm{~b})=\mathrm{q} 1 ; \quad \delta(\mathrm{q} 1, \mathrm{n})=\mathrm{q} 1 ; \quad \delta(\mathrm{q} 1, \mathrm{u})=\mathrm{q} 1 ; \quad \delta(\mathrm{q} 1, \mathrm{~h})=\mathrm{q} 1 ;$ $\delta(\mathrm{q} 1, \mathrm{~L})=\mathrm{q} 2 ; \quad \delta(\mathrm{q} 1, \mathrm{~S})=\mathrm{q} 3 ; \quad \delta(\mathrm{q} 1, \mathrm{k})=\mathrm{q} 1 ;$

$\delta(\mathrm{q} 2, \mathrm{~b})=\mathrm{q} 2 ; \quad \delta(\mathrm{q} 2, \mathrm{n})=\mathrm{q} 2 ; \quad \delta(\mathrm{q} 2, \mathrm{u})=\mathrm{q} 2 ; \quad \delta(\mathrm{q} 2, \mathrm{~h})=\mathrm{q} 2 ;$ $\delta(\mathrm{q} 2, \mathrm{~L})=\mathrm{q} 3 ; \quad \delta(\mathrm{q} 2, \mathrm{~S})=\mathrm{q} 4 ; \quad \delta(\mathrm{q} 2, \mathrm{k})=\mathrm{q} 2 ;$ $\delta(\mathrm{q} 3, \mathrm{~b})=\mathrm{q} 3 ; \quad \delta(\mathrm{q} 3, \mathrm{n})=\mathrm{q} 3 ; \quad \delta(\mathrm{q} 3, \mathrm{u})=\mathrm{q} 3 ; \quad \delta(\mathrm{q} 3, \mathrm{~h})=\mathrm{q} 3 ;$ $\delta(\mathrm{q} 3, \mathrm{~L})=\mathrm{q} 4 ; \quad \delta(\mathrm{q} 3, \mathrm{~S})=\mathrm{q} 5 ; \quad \delta(\mathrm{q} 3, \mathrm{k})=\mathrm{q} 3 ;$

$\delta(\mathrm{q} 4, \mathrm{~b})=\mathrm{q} 4 ; \quad \delta(\mathrm{q} 4, \mathrm{n})=\mathrm{q} 4 ; \quad \delta(\mathrm{q} 4, \mathrm{u})=\mathrm{q} 4 ; \quad \delta(\mathrm{q} 4, \mathrm{~h})=\mathrm{q} 4 ;$ $\delta(\mathrm{q} 4, \mathrm{~L})=\mathrm{q} 5 ; \quad \delta(\mathrm{q} 4, \mathrm{~S})=\mathrm{q} 6 ; \quad \delta(\mathrm{q} 4, \mathrm{k})=\mathrm{q} 4 ;$

$\delta(\mathrm{q} 5, \mathrm{~b})=\mathrm{q} 0 ; \quad \delta(\mathrm{q} 5, \mathrm{n})=\mathrm{q} 5 ; \quad \delta(\mathrm{q} 5, \mathrm{u})=\mathrm{q} 5 ; \quad \delta(\mathrm{q} 5, \mathrm{~h})=\mathrm{q} 5 ;$ $\delta(\mathrm{q} 5, \mathrm{~L})=\mathrm{q} 6 ; \quad \delta(\mathrm{q} 5, \mathrm{~S})=\mathrm{q} 7 ; \quad \delta(\mathrm{q} 5, \mathrm{k})=\mathrm{q} 0 ;$

$\delta(\mathrm{q} 6, \mathrm{~b})=\mathrm{q} 0 ; \quad \delta(\mathrm{q} 6, \mathrm{n})=\mathrm{q} 0 ; \quad \delta(\mathrm{q} 6, \mathrm{u})=\mathrm{q} 6 ; \quad \delta(\mathrm{q} 6, \mathrm{~h})=\mathrm{q} 6 ;$ $\delta(\mathrm{q} 6, \mathrm{~L})=\mathrm{q} 7 ; \quad \delta(\mathrm{q} 6, \mathrm{~S})=\mathrm{q} 8 ; \quad \delta(\mathrm{q} 6, \mathrm{k})=\mathrm{q} 0 ;$

$\delta(\mathrm{q} 7, \mathrm{~b})=\mathrm{q} 0 ; \quad \delta(\mathrm{q} 7, \mathrm{n})=\mathrm{q} 0 ; \quad \delta(\mathrm{q} 7, \mathrm{u})=\mathrm{q} 0 ; \quad \delta(\mathrm{q} 7, \mathrm{~h})=\mathrm{q} 7$ $\delta(\mathrm{q} 7, \mathrm{~L})=\mathrm{q} 8 ; \quad \delta(\mathrm{q} 7, \mathrm{~S})=\mathrm{q} 8 ; \quad \delta(\mathrm{q} 7, \mathrm{k})=\mathrm{q} 0 ;$

$\delta(\mathrm{q} 8, \mathrm{~b})=\mathrm{q} 0 ; \quad \delta(\mathrm{q} 8, \mathrm{n})=\mathrm{q} 0 ; \quad \delta(\mathrm{q} 8, \mathrm{u})=\mathrm{q} 0 ; \quad \delta(\mathrm{q} 8, \mathrm{~h})=\mathrm{q} 0 ;$ $\delta(\mathrm{q} 8, \mathrm{~L})=\mathrm{q} 8 ; \quad \delta(\mathrm{q} 8, \mathrm{~S})=\mathrm{q} 8 ; \quad \delta(\mathrm{q} 6, \mathrm{k})=\mathrm{q} 0 ;$

Jika dipetakan dalam tabel transisi, seperti tabel 2.

Tabel 2:Tabel transisi input

\begin{tabular}{|c|c|c|c|c|c|c|c|}
\hline$\delta$ & $\mathrm{b}$ & $\mathrm{n}$ & $\mathrm{u}$ & $\mathrm{h}$ & $\mathrm{L}$ & $\mathrm{s}$ & $\mathrm{k}$ \\
\hline $\mathrm{q} 0$ & $\mathrm{q} 0$ & $\mathrm{q} 0$ & $\mathrm{q} 0$ & $\mathrm{q} 0$ & $\mathrm{q} 1$ & $\mathrm{q} 2$ & $\mathrm{q} 0$ \\
\hline $\mathrm{q} 1$ & $\mathrm{q} 1$ & $\mathrm{q} 1$ & $\mathrm{q} 1$ & $\mathrm{q} 1$ & $\mathrm{q} 2$ & $\mathrm{q} 3$ & $\mathrm{q} 1$ \\
\hline $\mathrm{q} 2$ & $\mathrm{q} 2$ & $\mathrm{q} 2$ & $\mathrm{q} 2$ & $\mathrm{q} 2$ & $\mathrm{q} 3$ & $\mathrm{q} 4$ & $\mathrm{q} 2$ \\
\hline $\mathrm{q} 3$ & $\mathrm{q} 3$ & $\mathrm{q} 3$ & $\mathrm{q} 3$ & $\mathrm{q} 3$ & $\mathrm{q} 4$ & $\mathrm{q} 5$ & $\mathrm{q} 3$ \\
\hline $\mathrm{q} 4$ & $\mathrm{q} 4$ & $\mathrm{q} 4$ & $\mathrm{q} 4$ & $\mathrm{q} 4$ & $\mathrm{q} 5$ & $\mathrm{q} 6$ & $\mathrm{q} 4$ \\
\hline $\mathrm{q} 5$ & $\mathrm{q} 0$ & $\mathrm{q} 5$ & $\mathrm{q} 5$ & $\mathrm{q} 5$ & $\mathrm{q} 6$ & $\mathrm{q} 7$ & $\mathrm{q} 0$ \\
\hline $\mathrm{q} 6$ & $\mathrm{q} 0$ & $\mathrm{q} 0$ & $\mathrm{q} 6$ & $\mathrm{q} 6$ & $\mathrm{q} 7$ & $\mathrm{q} 8$ & $\mathrm{q} 0$ \\
\hline $\mathrm{q} 7$ & $\mathrm{q} 0$ & $\mathrm{q} 0$ & $\mathrm{q} 0$ & $\mathrm{q} 7$ & $\mathrm{q} 8$ & $\mathrm{q} 8$ & $\mathrm{q} 0$ \\
\hline $\mathrm{q} 8$ & $\mathrm{q} 0$ & $\mathrm{q} 0$ & $\mathrm{q} 0$ & $\mathrm{q} 0$ & $\mathrm{q} 8$ & $\mathrm{q} 8$ & $\mathrm{q} 0$ \\
\hline
\end{tabular}

Tabel 2 menjelaskan tentang perpindahan state sesuai dengan input yang masuk.

$\mathrm{S}=\{\mathrm{q} 0\}$

$\Delta=\{\mathrm{B}, \mathrm{N}, \mathrm{U}, \mathrm{H}, \mathrm{o}\}$

$\lambda=$ fungsi output untuk setiap transisi

$\lambda(\mathrm{q} 0, \mathrm{~b})=\mathrm{o} ; \quad \lambda(\mathrm{q} 0, \mathrm{n})=\mathrm{o} ; \quad \lambda(\mathrm{q} 0, \mathrm{u})=\mathrm{o} ; \quad \lambda(\mathrm{q} 0, \mathrm{~h})=\mathrm{o} ; \quad \lambda(\mathrm{q} 0, \mathrm{~L})=0 ;$ $\lambda(\mathrm{q} 0, \mathrm{~S})=\mathrm{o} ; \lambda(\mathrm{q} 0, \mathrm{k})=\mathrm{o}$;

$\lambda(\mathrm{q} 1, \mathrm{~b})=\mathrm{o} ; \quad \lambda(\mathrm{q} 1, \mathrm{n})=\mathrm{o} ; \quad \lambda(\mathrm{q} 1, \mathrm{u})=\mathrm{o} ; \quad \lambda(\mathrm{q} 1, \mathrm{~h})=\mathrm{o} ; \quad \lambda(\mathrm{q} 1, \mathrm{~L})=0 ;$ $\lambda(\mathrm{q} 1, \mathrm{~S})=0 ; \lambda(\mathrm{q} 1, \mathrm{k})=0$;

$\lambda(\mathrm{q} 2, \mathrm{~b})=\mathrm{o} ; \quad \lambda(\mathrm{q} 2, \mathrm{n})=\mathrm{o} ; \quad \lambda(\mathrm{q} 2, \mathrm{u})=\mathrm{o} ; \quad \lambda(\mathrm{q} 2, \mathrm{~h})=\mathrm{o} ; \quad \lambda(\mathrm{q} 2, \mathrm{~L})=\mathrm{o} ;$ $\lambda(\mathrm{q} 2, \mathrm{~S})=\mathrm{o} ; \lambda(\mathrm{q} 2, \mathrm{k})=\mathrm{o}$;

$\lambda(\mathrm{q} 3, \mathrm{~b})=\mathrm{o} ; \quad \lambda(\mathrm{q} 3, \mathrm{n})=\mathrm{o} ; \quad \lambda(\mathrm{q} 3, \mathrm{u})=\mathrm{o} ; \quad \lambda(\mathrm{q} 3, \mathrm{~h})=\mathrm{o} ; \quad \lambda(\mathrm{q} 3, \mathrm{~L})=\mathrm{o} ;$ $\lambda(\mathrm{q} 3, \mathrm{~S})=\mathrm{o} ; \lambda(\mathrm{q} 3, \mathrm{k})=\mathrm{o}$

$\lambda(\mathrm{q} 4, \mathrm{~b})=\mathrm{o} ; \quad \lambda(\mathrm{q} 4, \mathrm{n})=\mathrm{o} ; \quad \lambda(\mathrm{q} 4, \mathrm{u})=\mathrm{o} ; \quad \lambda(\mathrm{q} 4, \mathrm{~h})=\mathrm{o} ; \quad \lambda(\mathrm{q} 4, \mathrm{~L})=0 ;$ $\lambda(\mathrm{q} 4, \mathrm{~S})=0 ; \lambda(\mathrm{q} 4, \mathrm{k})=0$; 
$\lambda(\mathrm{q} 5, \mathrm{~b})=\mathrm{B} ; \quad \lambda(\mathrm{q} 5, \mathrm{n})=\mathrm{o} ; \quad \lambda(\mathrm{q} 5, \mathrm{u})=\mathrm{o} ; \quad \lambda(\mathrm{q} 5, \mathrm{~h})=\mathrm{o} ; \quad \lambda(\mathrm{q} 5, \mathrm{~L})=\mathrm{o} ;$ $\lambda(\mathrm{q} 5, \mathrm{~S})=\mathrm{o} ; \lambda(\mathrm{q} 5, \mathrm{k})=\mathrm{o}$;

$\lambda(\mathrm{q} 6, \mathrm{~b})=\mathrm{B} ; \quad \lambda(\mathrm{q} 6, \mathrm{n})=\mathrm{N} ; \quad \lambda(\mathrm{q} 6, \mathrm{u})=\mathrm{o} ; \quad \lambda(\mathrm{q} 6, \mathrm{~h})=\mathrm{o} ; \quad \lambda(\mathrm{q} 6, \mathrm{~L})=\mathrm{o} ;$ $\lambda(\mathrm{q} 6, \mathrm{~S})=\mathrm{o} ; \quad \lambda(\mathrm{q} 6, \mathrm{k})=\mathrm{o}, \mathrm{L} ;$

$\lambda(\mathrm{q} 7, \mathrm{~b})=\mathrm{B} ; \quad \lambda(\mathrm{q} 7, \mathrm{n})=\mathrm{N} ; \quad \lambda(\mathrm{q} 7, \mathrm{u})=\mathrm{U} ; \quad \lambda(\mathrm{q} 7, \mathrm{~h})=\mathrm{o} ; \quad \lambda(\mathrm{q} 7, \mathrm{~L})=\mathrm{o} ;$ $\lambda(\mathrm{q} 7, \mathrm{~S})=\mathrm{o} ; \quad \lambda(\mathrm{q} 7, \mathrm{k})=\mathrm{o}, \mathrm{L}, \mathrm{S} ;$

$\lambda(\mathrm{q} 8, \mathrm{~b})=\mathrm{B} ; \quad \lambda(\mathrm{q} 8, \mathrm{n})=\mathrm{N} ; \quad \lambda(\mathrm{q} 8, \mathrm{u})=\mathrm{U} ; \quad \lambda(\mathrm{q} 8, \mathrm{~h})=\mathrm{H} ; \quad \lambda(\mathrm{q} 8, \mathrm{~L})=\mathrm{L} ;$ $\lambda(\mathrm{q} 8, \mathrm{~S})=\mathrm{S} ; \lambda(\mathrm{q} 8, \mathrm{k})=0, \mathrm{~L}, \mathrm{~S} ;$

Jika dipetakan dalam tabel transisi, seperti tabel 3.

Tabel 3: Tabel transisi output

\begin{tabular}{|c|c|c|c|c|c|c|c|}
\hline$\delta$ & $\mathrm{b}$ & $\mathrm{n}$ & $\mathrm{u}$ & $\mathrm{h}$ & $\mathrm{L}$ & $\mathrm{S}$ & $\mathrm{k}$ \\
\hline $\mathrm{q} 0$ & $\mathrm{o}$ & $\mathrm{o}$ & 0 & 0 & 0 & 0 & 0 \\
\hline $\mathrm{q} 1$ & 0 & 0 & 0 & 0 & 0 & 0 & 0 \\
\hline $\mathrm{q} 2$ & 0 & 0 & 0 & 0 & 0 & 0 & 0 \\
\hline $\mathrm{q} 3$ & 0 & 0 & 0 & 0 & 0 & 0 & 0 \\
\hline $\mathrm{q} 4$ & 0 & 0 & 0 & 0 & 0 & 0 & 0 \\
\hline $\mathrm{q} 5$ & $\mathrm{~B}$ & 0 & 0 & 0 & 0 & 0 & 0 \\
\hline q6 & $\mathrm{B}$ & $\mathrm{N}$ & 0 & 0 & 0 & 0 & $\mathrm{o}, \mathrm{L}$ \\
\hline $\mathrm{q} 7$ & $\mathrm{~B}$ & $\mathrm{~N}$ & $\mathrm{U}$ & 0 & 0 & 0 & $0, \mathrm{~L}, \mathrm{~S}$ \\
\hline $\mathrm{q} 8$ & $\mathrm{~B}$ & $\mathrm{~N}$ & $\mathrm{U}$ & $\mathrm{H}$ & $\mathrm{L}$ & $\mathrm{S}$ & $\mathrm{o}, \mathrm{L}, \mathrm{S}$ \\
\hline
\end{tabular}

Dengan tabel 3 tersebut, kita dapat mengetahui input yang akan dikeluarkan, sebagai contoh pada state q8 yang mengeluarkan banyak pilihan output, jika mendapatkan input b, maka akan keluar output B (Buavita), jika mendapatkan input $\mathrm{n}$, maka akan keluar output $\mathrm{N}$ (Nescafe), jika mendapatkan input $\mathrm{u}$, maka akan keluar output $\mathrm{U}$ (Ultra Milk), jika mendapatkan input $\mathrm{h}$, maka akan keluar output $\mathrm{H}$ (Hilo). Bila mendapat input L(500), maka output-nya adalah L lagi, dan bila inputnya S (1000), output-nya juga S. State q8 adalah state terakhir, sehingga bila diberi input nilai uang lagi (L dan S),maka state tidak akan beranjak dan memuat nilai kelebihan uang tersebut. Bila inputnya adalahk (kembalian), maka kelebihan dari L dan S tadi akan dikeluarkan sesuai dengannilainya.

Output: Dari hasil kalkulasi, diperoleh output yang akan dikeluarkan aplikasi. Output berupa gambar minuman yang dipilih, serta angka yang menyatakan uang kembalian (jika nominal uang lebih besar dari harga yang tertera).

\section{HASIL DAN PEMBAHASAN}

\section{Form Simulasi Vending Machine}

Rancangan tampilan form vending machine dapat dilihat pada gambar 6, simulasi tersebut sudah memvisualisasikan gambaran dari vending machine tersebut yang memfasilitasi untuk pembelian minuman.

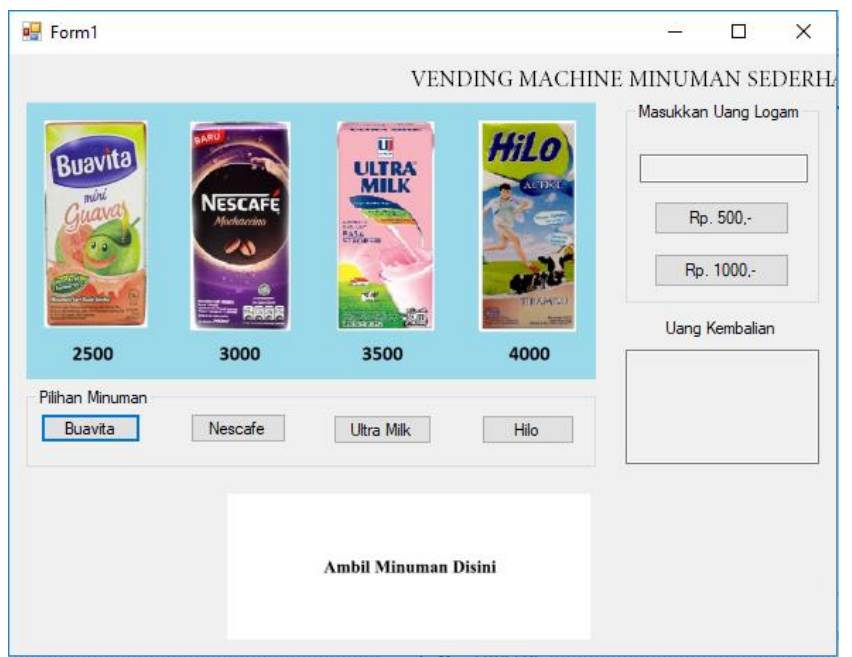

Gambar 6: Simulasi Vending Machine

Pada gambar 7 dapat dilihat terdapat fasilitas memasukkan uang, hanya ada uang Rp. 500 dan Rp. 1000 dikarenakan input berupa koin (uang logam), jika kita input Rp. 500 maka dilayar akan tercetak nominal yang sama dengan apa yang diinputkan, kemudian jika kita melakukan input selanjutnya, nominal akan berubah (bertambah) sesuai dengan nominal yang ditambahkan.

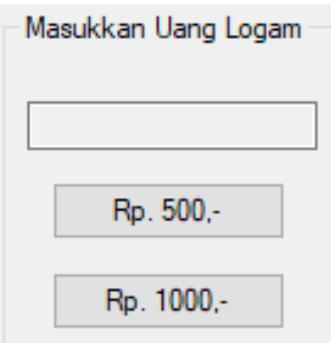

Gambar 7: Fasilitas Input Koin

Kemudian pada gambar 8 dapat dilihat ada fasilitas uang kembalian, hal itu bisa terjadi jika nominal yang dimasukkan lebih besar dari harga minuman yang dipilih, dan akan kosong jika nominal uang yang dimasukkan sama atau bahkan kurang dari harga minuman yang dipilih.

\section{Uang Kembalian}

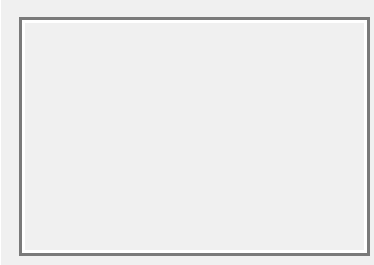

Gambar 8: Fasilitas Uang Kembalian 
Sebagai contoh, jika kita ingin membeli minuman Nescafe harga Rp. 3.000,- maka akan muncul tampilan seperti gambar 9.

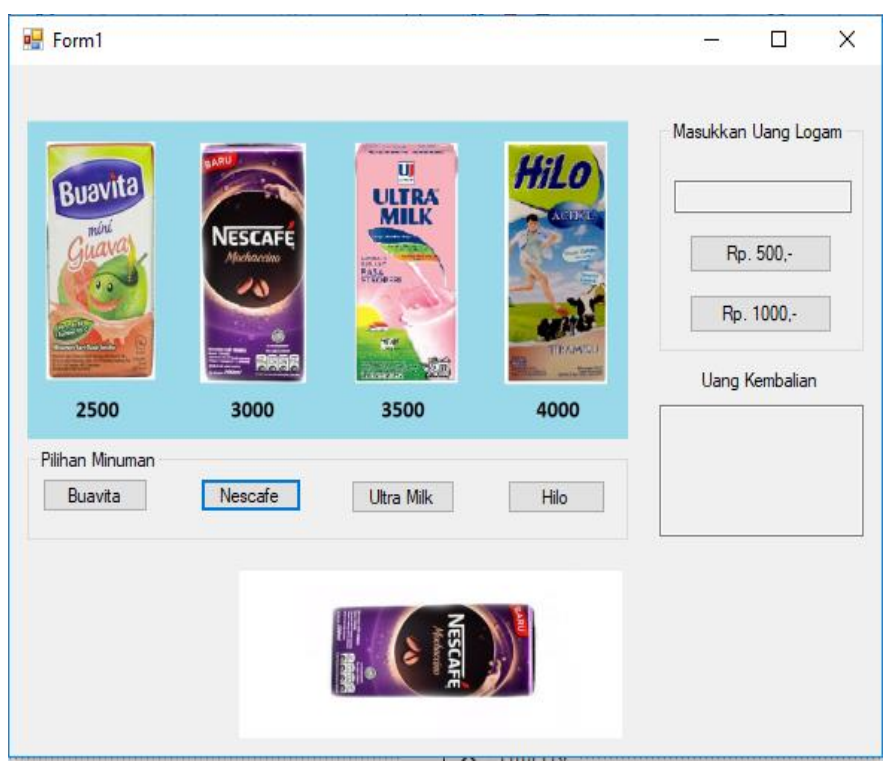

Gambar 9: Hasil Keluaran dari Vending Machine

Minuman Nescafe bisa keluar dikarenakan kita telah menginput nominal yang sesuai dengan harga minuman tersebut, dan tidak ada uang kembalian dikarenakan harga yang dimasukkan sama dengan dan atau tidak melebihi dari harga minuman.

\section{KESIMPULAN DAN SARAN}

Penggunaan finite state automata pada vending machine sudah sangat sesuai didalam cara kerjanya, finite state sebagai dasar dari pengoperasian simulasi tersebut sudah menjelaskan detail alur dari apa yang user lakukan, sehingga prosesnya mudah dipahami. Dan diharapkan user dapat lebih paham akan hal tersebut.

\section{DAFTAR PUSTAKA}

[1] V. V. S. Vijay, A. Monisha, S. Sadulla, and J. Prathiba, "Design and Implementation of an automatic Beverages Vending Machine and its performance evaluation using Xilinx ISE and Cadence," pp. 4-9, 2013.

[2] K. Kim, D. Park, H. Bang, G. Hong, and S. Jin, "Smart Coffee Vending Machine Using Sensor and Actuator Networks," pp. 71-72, 2014.

[3] M. S. A. S, M. Syai, J. Endrasmono, S. T. Sarena, L. Subiyanto, and A. S. Setyoko, "Smart Vending Machine Based on SMS Gateway For General Transactions," no. 2, pp. 34-39, 2017.

[4] N. Kulmukhanova, A. Daribay, I. Temirtayev, and U. Bassembek, "ZhardEM Medicine Vending Machine," 2018 Int. Conf. Comput. Netw. Commun., pp. 108-113, 2018.

[5] C. Wenshan, H. Yanqun, and L. Minyang, "Influential factors of vending machine interface to enhance the interaction performance," pp. 1-4, 2015.

[6] V. Vaid, "Comparison of different attributes in modeling a FSM based vending machine in 2 different styles," no. Ices, pp. 18-21, 2014.

[7] Y. Shoji, K. Nakauchi, and W. Liu, "Community-based wireless IoT infrastructure using ubiquitous vending machines," pp. 3-7, 2016.

[8] V. P. Semenov, V. V Chernokulsky, and N. V Razmochaeva, "The Cashless Payment Device for Vending Machines - Import Substitution in the Sphere of Vending," pp. 798-802, 2017.

[9] A. Ramzan, S. Rehman, A. Perwaiz, U. I. Number, and L. C. D. L. Crystal, "RFID Technology : Beyond CashBased Methods in Vending Machine," pp. 189-193, 2017.

[10] H. Namie, "Positioning-Based ICT Infrastructure Platform - Smart Vending Machine -," pp. 446-447, 2014.

[11] F. Muhammad and N. Faradilla, "User Experience Evaluation on the Usage of Commuter Line Train Ticket Vending Machine,” pp. 164-170, 2017. 
